\title{
Orchelimum gladiator Bruner, 1891: An Addition to the Prey Record of the Great Black Wasp, Sphex pensylvanicus Linnaeus, 1763 (Hymenoptera: Sphecidae: Sphecinae) ${ }^{1}$
}

\author{
G. K. Lechner ${ }^{2}$
}

The Great Black Wasp, Sphex pensylvanicus Linnaeus, 1763 is a known predator of katydids (Orthoptera: Tettigoniidae) and is rather catholic in its choice of prey seemingly taking any katydid species available. In a previous paper (Lechner 2016), I stated that five species placed in four genera of katydids have been reported as prey items of S. pensylvanicus. Also, I reported four confirmed katydid species that I took from $S$. pensylvanicus that nest in the soil behind a vertical retaining wall on my residential property in Sioux City, Iowa. Herein, I add the Gladiator Meadow Katydid, Orchelimum gladiator Bruner, 1891 (Figures 1 and 2, next page), to the prey record of S. pensylvanicus. I took this paralyzed katydid from its captor female $S$. pensylvanicus on 28 August 2017. At that time, the wasp was attempting to enter her nest with her prey item in the north lot line retaining wall.

\section{Acknowledgments}

Many thanks to Dr. Thomas J. Walker (University of Florida, Gainesville, Florida, USA) for identifying the specimen of Orchcelimum gladiator. This katydid was donated to the Ensiferan Collection at the University of Florida.

\section{Literature Cited}

Lechner, G. K. 2016. Interesting incidents with Sphex pensylvanicus Linnaeus, 1763 (Hymenoptera: Sphecidae) wasps and their prey items in Sioux City, Iowa, U.S.A. Life: The Excitement of Biology 4:27-31. https://blaypublishers.files.wordpress.com/2016/07/lechner-leb-41-interestingincidents-with-sphex-pensylvanicus-linnaeus.pdf

\footnotetext{
1 Received on October 17, 2017. Accepted on October 21, 2017. Last changes received on November 1, 2017

${ }^{2}$ Sioux City, Iowa, USA. E-mail: garylechner22@gmail.com
}

DOI: 10.9784/LEB5(2)Lechner.01

Electronically available on November 06, 2017. Mailed on November 06, 2017. 

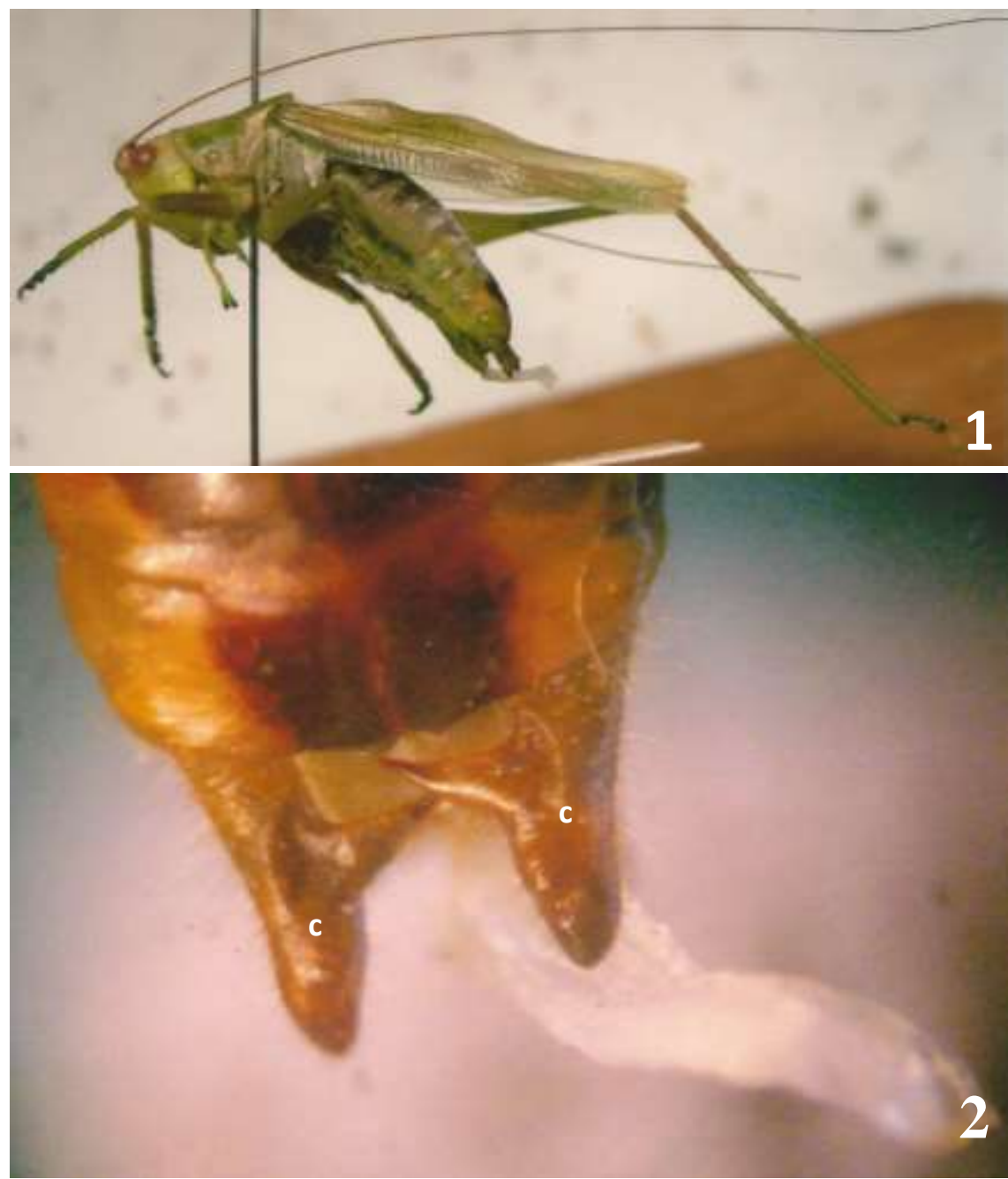

Figures 1-2. Orchelimum gladiator Bruner, 1891 male. 1. Overall view. Captured on August 28, 2017. Head to apex of abdominal terminalia, $19 \mathrm{~mm}$; head to apex of wing tegmina, $25 \mathrm{~mm}$. 2. Close-up of abdominal apex showing cerci, c. 